\title{
A INFÂNCIA DEIXADA NA ESTRADA: BUSCÁ-LA ONDE ELA FICOU
}

Miguel G. Arroyo *

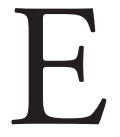

stamos aqui para celebrar a memória, para celebrar as marcas do humano de Angel Pino. As Marcas do Humano, um dos trabalhos marcantes de Angel Pino empenhado em "desvendar a natureza do 'Humano', sondando as marcas deixadas pelo caminho". Empenhado em "[...] descobrir que a história de cada um de nós faz parte de uma história maior e que ambas as histórias se constroem mutuamente [...]". Nos tornamos humanos nas vivências humanas e resistindo às vivências desumanas que nem sempre escolhemos. Que traços destacar nas marcas do humano em Angel Pino?

Ir à sua infância, às formas de vivê-la. O percurso de nossas infâncias teve vivências próximas. Dialogávamos sobre esse percurso comum: filhos de famílias e de lugares próximos. Havia uma vivência que voltava em nossas memórias. Além dessa proximidade de lugar havia outra mais forte em nossas infâncias: ambos éramos filhos de pais na guerra civil espanhola. Vivência de filhos de pai na guerra que marcaram nossa infância e de milhares de crianças. Que marcas do humano deixaram essas vivências de filhos de pais obrigados a ir à guerra, arrancados do lugar, da família?

Angel Pino, no último encontro, me lembrou da marca mais forte de sua infância: disse-me, "Arroyo, teu pai voltou da guerra vivo, meu pai não voltou vivo". Essas identidades de infância, de filhos da guerra, de pai que não voltou vivo, ou de pai que voltou doente, aproxi-

\footnotetext{
* Universidade Federal de Minas Gerais (UFMG), Faculdade de Educação. E-mail de contato: gn.arroyo@gmail.com.
} 
mavam nossas memórias da infância. Memórias como tantas memórias não estão profundamente marcadas por como vivemos a infância? As primeiras marcas do humano e do desumano não vêm da infância?

Lembro-me de ter perguntado para Angel: "Você que tanto escreve sobre a infância, sobre o desenvolvimento humano da infância, será que não tem nada a ver com a forma como você viveu a sua infância?". Tem tudo a ver, respondeu. Quis destacar essa marca do humano em Angel Pino: que é difícil entender o intelectual do desenvolvimento humano, de desenvolvimento infantil, sem essa vivência forte que ele teve da infância. Ao narrar sua biografia, ele diz: "nasci em tempos difíceis de vir ao mundo".

Diante dessa memória pessoal tão forte, como se esquecer de tantas crianças que nasceram e nascem em tempos difíceis de vir ao mundo? Tempos de guerra, de tantas outras guerras, de tantas formas de perder os pais, que mal tiveram tempo de conhecer, tempos difíceis de viver, de destruição de vidas, de vidas mal vividas...

São as marcas do humano trazidas das vivências da infância que instigaram o pensador - comprometido com as possibilidades e os limites do desenvolvimento humano de tantas infâncias mal vividas. Uma sintonia forte de Angel Pino com tantas infâncias vitimadas sem direito a viver a infância digna, obrigadas a viver uma infância sempre ameaçada pelos tempos difíceis de vir ao mundo, de viver-sobreviver neste mundo, na desnutrição, 17 milhóes na pobreza extrema, em lugares de corpos precarizados.

Angel Pino como pessoa, como pensador, estava à procura da infância. Lembro-me de uma conversa em que comentou: "Arroyo, li uma epígrafe de Fernando Pessoa em um dos teus livros, e me identifiquei: 'A criança que fui chora na estrada. Deixei-a ali quando vim ser quem sou... Quero ir buscar quem fui onde ficou...”. É difícil entender a centralidade que Angel Pino dá à infância, ao desenvolvimento da infância, sem entender esse voltar-se à procura da infância, onde a deixou, que não viveu, o pai que não voltou. Gostaria de dar esse depoimento, para, talvez, ajudar-nos a entender toda essa vivência da infância, que se revela ao lado do Angel Pino intelectual e escritor. Humano à procura das marcas do humano e do desumano na infância. 
O que chama a atenção nos textos do Angel Pino dentro dessa perspectiva? Primeiro, seus esforços para que a psicologia do desenvolvimento, que ele tanto trabalha, junto com a psicologia educacional, não reforcem uma concepção de infância distante da infância real. Pino estava atrás da infância real vivida, "mal-vivida" de milhóes de crianças, especialmente porque tinha vivido os tempos de infância com um realismo forte, um realismo cruel e ele não se deixava enganar por uma visão romântica da infância, nem romântica do seu desenvolvimento humano e nem do desenvolvimento cultural. Ele preferia trabalhar com a infância como é, não uma infância como um devir, como um tempo de passagem, um tempo que um dia deverá ser uma vida adulta. Para Angel, a infância é importante nas condições reais de vivê-la ou "mal-vivê-la". Sempre insistia muito nas formas de ver a infância, na necessidade de reconciliar o olhar das teorias sobre a infância e a infância real.

Uma proposta ousada: reconciliar as teorias do desenvolvimento humano, as teorias pedagógicas, a própria pedagogia com a infância real. Quando as teorias do desenvolvimento humano ou da educação da infância se esquecem da infância real, se esquecem delas mesmas como teorias.

No texto arguto, "Direitos e realidade social da criança no Brasil. A propósito do 'Estatuto da Criança e do Adolescente"” (PINO, 1990), Angel Pino vê o Estatuto da Criança e do Adolescente (ECA) como uma reconciliação política, legal, jurídica com a infância. Até onde essa reconciliação avançou no pensamento social, político, psicológico e pedagógico com a infância real? Ainda predominam concepçóes generalistas de infância. Para Angel Pino a reconciliação só passará pelo reconhecimento da infância real que, em razão das condiçóes econômicas e sociais, se vê predeterminada a um tipo de existência marginalizada.

A preocupação com a infância marginalizada é uma constante no olhar de Angel Pino - "Uma pedagogia para o menor marginalizado". Para ele, a pedagogia do menor "marginalizado" é uma antipedagogia. A verdadeira pedagogia só pode ser denunciadora de um sistema social excludente e marginalizante, denunciadora de uma concepção de educação alienante e elitista. (PINO, 1980, p. 57) Angel Pino propóe uma pedagogia que faça da realidade do homem, da sociedade e da cultura o ponto de partida da reflexão pedagógica. 
Uma análise, uma denúncia e uma proposta que parecem escritas para hoje. Denúncia de extrema atualidade em tempos de rebaixamento da maioridade penal. Já em 1980 chamava atenção para "[...] a preocupação com o problema do menor como uma reação da defesa - exigindo medidas repressivas mais enérgicas em nome da segurança social [...]" (p. 47).

Angel nos provoca a perguntar-nos: crianças, adolescentes violentos ou violentados? Assassinos culpados ou inocentes? De quem é a culpa? Suas análises nos advertem que o problema dos menores submetidos à justiça penal vem de um capitalismo selvagem, onde a prosperidade de uma minoria insignificante se constrói sobre a miséria da grande massa popular... O menor "marginalizado" é produto de estruturas sociais, econômicas e políticas geradoras do processo de marginalização crescente das classes trabalhadoras... (p. 48).

Que falta faz esse olhar de Angel Pino sobre a juventude, adolescência, infância pobre, negra nem mais vista como "marginal", mas condenada como infratores, delinquentes para justificar o rebaixamento da maioridade penal e sua entrega à justiça penal. Já em 2007 Angel Pino (2007), no texto "Violência, Educação e Sociedade", trazia à discussão uma realidade que exigia reflexóes aprofundadas e que se tornou atualíssima:

[...] a violência evoca a ideia de desordem: 'desordem da razão', 'desordem moral' e 'desordem social' [...] Mas a história social moderna [...] revela revela que isso (a desordem) não se aplica a todos os indivíduos, mas apenas, ou principalmente a alguns, os oriundos das classes populares, cidadáos sem cidadania por não terem propriedade. Essas classes são vistas como a causa e origem do crime e da violência na sociedade, das quais esta tinha que se proteger, inventando a 'prisão' [...] (p. 774).

Pino já anunciava que o rebaixamento da idade penal estava a inventar a 'prisão' para que os adolescentes - jovens populares pobres, negros - fossem condenados como violentos, infratores. Tempos em que a democracia racial e o racismo silencioso se revelam segregadores, 
condenatórios até no parlamento, nas leis, na justiça e na sociedade. Não estamos em tempos difíceis para o que Angel Pino propunha e porque lutava: a reconciliação jurídica, política, legal com a infância-adolescência? Hoje as guerras racistas estão declaradas contra jovens-adolescentes-crianças pobres, negras extermináveis em nome da ordem social que, supostamente, ameaçam com sua delinquência infanto-juvenil. Estaríamos ao menos em tempos de reconciliação da pedagogia, da escola com essas infâncias, adolescências pobres, negras que lutam por escola e proteção? Questôes que persistem como um legado das marcas do humano de Angel Pino.

Por que essa sua ênfase na reconciliação política, legal, teórica com a infância real, na existência social marginalizada? Sem dúvida, porque suas formas de viver a infância foram tão duras, tão marcantes, tão desestruturantes do seu próprio viver da infância, pela solidariedade intelectual e humana com os milhóes de vida em tempos difíceis de viver.

Formas de viver de tantas crianças que questionam concepções de infância que não são realistas. A visão "etapista" de desenvolvimento humano, ele não aceitava. Infância é infância. Bem vivida, mal vivida, revivida, mas é nessa infância real em que temos que buscar as teorias, alimentar as teorias do desenvolvimento humano e da educação. Ele falava constantemente que era necessário entender a infância, envolvida, condicionada pelas tensôes sociais, políticas, econômicas, como ele viveu a infância.

Ciente dessas tensôes, dessas condiçóes se aproxima da construção cultural do ser humano. A cultura não é algo que paira acima da natureza, mas a natureza é o fluxo da vida, e a materialidade do viver marca profundamente a cultura. Para Angel Pino, a cultura não paira sobre o viver real, ao contrário, o viver real, o trabalho do campo, a cultura da terra, a cultura do trabalho, a produção do ser histórico-social é o determinante do ser cultural. A cultura não é só produto, mas produtora e produção do desenvolvimento humano. A cultura é determinada pela totalidade do social. A cultura, o desenvolvimento cultural humano de uma criança, de um adolescente, do ser humano, é inseparável da história. O desenvolvimento humano é atrelado a como os seres humanos se relacionam com a produção da existência, com o comer, vestir, ter um teto. 
Angel Pino, como Paulo Freire, busca as infâncias deixadas na estrada, à margem, proibidas de ser, roubadas em sua humanidade, mas em lutas incessantes de recuperação de sua humanidade. Liçóes para reconciliar a pedagogia com o desenvolver-se e o aprender de processos de desenvolvimento humano, cultural, ético, identitário de infâncias quebradas, mas resistentes e que teimam por lugar nas escolas. Liçóes para os currículos de pedagogia, de licenciatura, formadores das artes de entender essas infâncias e as tensóes do seu desenvolvimento humano, por que direitos humanos lutam e lhes são negados.

No texto "Direitos e realidade social da criança no Brasil" (PINO, 1990, p. 436), coloca com destaque o direito à vida, náo a qualquer forma de existência. O desenvolvimento cultural humano exige formas de vida, de existência humanas. "A pobreza material não é, em si, sinônimo de pobreza social-cultural [...] mas quando a pobreza material é confinada em meios social e culturalmente pobres, então compromete-se, seriamente, o desenvolvimento humano da criança [...]" (p. 72).

Marcas constantes do olhar humano em Angel Pino. De denunciar o des-humano, in-humano no viver de tantas infâncias. Como repensar o desenvolvimento humano da infância, em vidas infantis tão precarizadas, em corpos tão precarizados? Como não perder o olhar dessa infância real como Angel Pino nunca perdia o olhar de suas vivências tão reais de infância? Fazendo a persistente volta à infância com Fernando Pessoa: "A infância que fui chora na estrada. Deixei-a ali quando vim ser quem sou... Quero ir buscar quem fui, onde ficou...".

Marcas fortes do humano em Angel Pino pensador, educador que manteve uma sensibilidade denunciante, atenta a essas infâncias-adolescências que a sociedade deixa na estrada, às margens de um justo, digno, humano viver. Lições para o pensamento pedagógico, para a formação de educadores/as comprometidos com buscar onde essa infância ficou. 


\section{REFERÊNCIAS}

PINO, A. As marcas do humano. São Paulo: Cortez, 2005. . Violência, educação e sociedade. Educ. Soc., n. 100, 2007. - Direitos e realidade social da infância no Brasil. A propósito do "Estatuto da Criança e do Adolescente”. Educ. Soc., n. 36, 1990. . Uma pedagogia para o menor "marginalizado". Educ. Soc., 1980.

Recebido em 15 de junho de 2015.

Aprovado em 30 de julho de 2015.

DOI: http://dx.doi.org/10.1590/CC0101-32622015V35ESPECIAL154114 